\title{
Theoretically Consistent Temporal Ordering Specification in Spatial Hedonic Pricing Models Applied to the Valuation of Aircraft Noise
}

\author{
Sotirios Thanos , Abigail L. Bristow*, Mark R. Wardman ${ }^{* *}$
}

\begin{abstract}
Incorporating spatial econometric tools in Hedonic Pricing (HP) models for environmental valuation has become the standard approach in the literature. The effect of house prices on other house prices is taken into account and usually measured by distance or contiguity in spatial weight matrices. Disaggregate house sale datasets are composed from observations each at a specific location and time. Nevertheless, the symmetric spatial weight matrices commonly employed in HP studies ignore the temporal dimension in disaggregate house sale data. Thus not only are previous house sales taken to affect subsequent house prices, but so do future house sales. However, information does not travel backwards in time; hence there is a clear theoretical impossibility of actual future prices affecting current/past prices. Estimates derived from HP models where spatial dependence is incorrectly specified or ignored will exhibit inaccuracies. This paper proposes an alternative specification of spatial weights in HP that includes spatial effects on each sale price only from preceding house sales. The temporal aspect of spatial effects is then developed further by specifying a time decay rate to capture the diminishing effect over time of preceding sale prices to succeeding house prices. This novel specification of spatial weight matrices is shown to have a significant effect on estimates of house price depreciation from aircraft noise. Monetary values of aircraft noise externality are successfully derived from the HP models for Athens Airport.
\end{abstract}

Keywords: Spatial Econometrics, Spatial Autocorrelation, Aircraft Noise, Environmental Valuation, Hedonic Pricing, Time Decay

JEL classifications: C21, Q51, Q53, R41

$\wedge$ Corresponding Author, School of Built Environment, Heriot-Watt University, EH14 4AS, Edinburgh, UK,

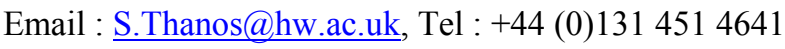

* School of Civil and Building Engineering, Loughborough University

** Institute for Transport Studies, University of Leeds 


\section{Introduction}

Noise disturbance is a serious environmental issue and a key externality of the aviation sector, raising health, economic and social concerns (Berglund et al., 1999; Miedema, 2007). Around 6.9 million people in Europe are exposed to aviation noise levels exceeding 55dBA and the numbers are expected to grow in the absence of further policy intervention (European Environment Agency, 2010). Valuation of the costs of aircraft noise annoyance can inform policy and appraisal. Hedonic Pricing (HP) techniques are traditionally relied upon to identify the impact of aviation noise on house prices (Nelson, 2008).

HP posits that the price of a composite commodity, such as housing, is a function of its characteristics, including the level of quietness (absence of noise). The quantity of hedonic studies on aircraft noise is such that a number of meta-analyses have been carried out. The most recent by Wadud (2010) included 53 estimates of house price depreciation from aircraft noise and concluded that a $1 \mathrm{dBA}$ change in aircraft noise levels leads to house price depreciation between $0.45 \%$ and $0.64 \%$. This estimate is broadly consistent with earlier analysis by Nelson (2004) and the early review by Nelson (1980) though somewhat lower than the estimates of Schipper et al. (1998) of $0.9 \%$ to $1.3 \%$. Whilst aircraft noise exposure is a negative externality, distance to the airport is often found to positively affect house prices (Tomkins et al., 1998), underlining the importance of the spatial dimension in such analysis.

The notion of spatial dependence stems from the first law of geography stating that "everything is related to everything else, but near things are more related than distant things" (Tobler 1970, pp. 236). During the past decade spatial econometrics has moved to the mainstream of applied econometrics and social science methodology (Anselin, 2010). Consequently, the scope of spatial econometrics has been further developed and broadened from the cross-sectional to the space-time domain (Anselin, 2006). Spatial econometrics is defined as "a subset of econometric methods that is concerned with spatial aspects present in cross-sectional and space-time observations. Variables related to location, distance and topology are treated explicitly in model specification; estimation; diagnostic checking and prediction" (Anselin, 2006, pp. 902). We are interested here in the case of spatial dependence that typically takes the form of weighted averages of observations for the 'neighbours' of a 
given location (Anselin, 2010). Spatially lagged variables are included to capture these effects, specified by a spatial weights matrix.

A number of studies have now combined spatial econometrics and HP models to value environmental attributes and transportation noise; examples include Conway et al. (2010), Andersson et al. (2010), Day et al. (2007), Hui et al. (2007) and Kim et al. (2003). A few studies have also combined spatial econometrics and HP models to produce aircraft noise valuation estimates (Bateman et al., 2004; Salvi, 2008; Cohen and Coughlin, 2008; Dekkers and Van der Straaten, 2009; Chalermpong, 2010), whilst Theebe (2004) combined rail, road and aircraft noise into a single noise index. Not all of these studies produce statistically significant HP estimates for aircraft noise and there are also some shortcomings in the treatment of aircraft noise in the HP modelling regarding the quality of the noise data and the treatment of background noise that are examined in detail in section 5 .

Anselin (2002, pp. 259) stresses that "there is very little formal guidance in the choice of the 'correct' spatial weights in any given application". This does not mean that there are no cases where the spatial weight specification is plainly incorrect. Most HP models are based on analysis of disaggregate house sale data, composed from observations each at a specific location and time. Spatial distance or contiguity is normally the only factor taken into account when specifying spatial weights for such data. However, there is an element of temporal ordering in disaggregate house sales datasets that ought to be taken into account. Ignoring the arrow of time produces paradoxical assumptions, such as a house sale price being affected by house sales that have not taken place yet. Henceforth, this is termed the "temporal ordering inconsistency", where interdependence of house prices is assumed instead of the correct unidirectional effect from earlier to subsequent house sales only. Even though expectations and speculation for future prices or forecasting may well affect current prices, all these strictly depend on information from the past and the present. Information does not travel backwards in time; hence there is a clear theoretical impossibility of actual future prices affecting current prices.

Temporal ordering has been recognised and accounted for in the real estate literature, as part of modelling the spatiotemporal patterns of house prices to produce robust house price indices. To that effect spatiotemporal models on panel data have been employed, often using HP model results as inputs (Pace et al., 1998; Gelfand et al., 2004). Can and Megbolugbe 
(1997), accounting for spatial dependence in house price index construction, allow only prior sales to influence house prices in their HP models, directly addressing the temporal ordering inconsistency. In section 4 we discuss their approach and its shortcomings, improving the methodology and applying it to environmental externality valuation.

The HP literature valuing environmental commodities does not appear to recognise the temporal ordering issue. Judging from the information provided about the nature of the data and the specification of spatial weights in the published papers, some of the aircraft noise HP studies (Chalermpong, 2010; Dekkers and Van der Straaten, 2009; Salvi, 2008; Theebe, 2004) and some looking at other environmental characteristics (Conway et al., 2010; Andersson et al., 2010; Hui et al., 2007) suffer from temporal ordering inconsistencies. Others, for example, Cohen and Coughlin (2008) and Bateman et al. (2004) attempt to avoid this issue by assuming that the house sale observations cover a single time period (i.e. a year) so no temporal ordering is imposed in their data. Kim et al. (2003) avoid the temporal ordering inconsistency, as their models are not based on house sales, but on survey data and respondents' estimates of their current house value. The spatial interaction is between geographical areas, where interrelationship is a reasonable assumption (Franzese, and Hays 2008).

The key contribution of this paper is to propose an elegant solution to the temporal ordering inconsistency and to demonstrate that the treatment of this inconsistency affects the estimation of aircraft noise depreciation. We also go a step further forward to specify a time decay rate capturing the over time diminishing effect of preceding sale prices to succeeding house prices. Additionally, the specification of aircraft noise in our models employs continuous noise data, explicitly including an allowance for background noise and avoiding the imposition of artificial thresholds (Thanos et al., 2011; Andersson et al., 2010), which we believe is an advance on previous practice in HP studies valuing aircraft noise.

The structure of this paper is as follows. Section 2 briefly discusses the theoretical background of the HP method. Section 3 describes the housing data and the derived geographical information. Section 4 explains spatial dependence, the approaches in the literature and our approach. Section 5 illustrates the shortcomings of aircraft noise treatment in the recent spatial HP literature and discusses our approach to aircraft noise modelling. 
Section 6 presents the HP modelling methodology and discusses the HP results. The conclusions follow in Section 7.

\section{Hedonic Pricing}

Rosen's (1974) two stage hedonic pricing approach was an important theoretical contribution that has become the cornerstone of most empirical work on housing markets. In the first stage, using data on house prices and characteristics, the hedonic price schedule is estimated, from which implicit marginal prices for housing characteristics are calculated (Nelson, 2008). However, implicit prices are market specific, reflecting only the particular situation of supply and demand that exist in a given property market and offering little indication of the conditions and marginal prices in other housing markets (Day et al., 2007). The second stage involves the marginal prices of a characteristic, combined with data on occupants' income and other socioeconomic variables, to estimate an inverse demand function (Nelson, 2008). This is a theoretically and analytically challenging task whilst the problem is in essence quite simple. Information is required on at least two points along the length of a household's demand curve, whereas data from a single housing market provide just one such point (Day et al., 2007).

Only Day et al. (2007) have applied the second stage HP approach in noise valuation and estimated an inverse demand function for road traffic and rail noise. All other noise valuation studies, including our approach, are estimating the first stage hedonic pricing schedule, reporting marginal prices of housing characteristics. The first stage hedonic price function $(P)$ of a composite commodity, housing in this case, may be written as:

$P=P(\gamma, Z)$

where $Z=\left[\mathrm{z}_{1}, \ldots, \mathrm{z}_{\mathrm{m}}\right]$ is a vector of utility bearing characteristics and $\gamma$ is aircraft noise exposure. The slope of the HP price function can be used to determine the consumer's marginal willingness to pay for a given commodity (characteristic), since in optimum it equals her marginal rate of substitution between the price of the commodity and any of the other housing characteristics (Rosen, 1974; Andersson et al., 2010). This marginal WTP for aircraft noise is: 
$M W T P=\frac{\partial P(\gamma, Z)}{\partial \gamma}$

Eq. 2 only shows the marginal WTP in optimum, obtained by the information of individuals' behaviour at a point in time; it does not reveal the underlying preference structure (Andersson et al., 2010). Moreover, welfare measurements are not possible using only marginal prices, unless the environmental change affects a small number of houses relative to the size of the market (Palmquist, 1992). This special case of a localised externality is applicable to our research context as we only examine a small part of the housing market of metropolitan Athens.

\section{Housing Data}

This study employs data on 1613 house sales from 1995 to the beginning of 2001, acquired by local real estate consultants ${ }^{1}$ around Athens International Airport (AIA). Aircraft noise had been a very important issue in this densely populated area (Charalampakis, 1980), which had more than 350,000 residents in 2001 (National Statistical Service of Greece, 2003).

The data include information about the basic structural characteristics of each house, such as the square meters of the floor for the living space ${ }^{2}$, construction year, sale date, number of rooms ${ }^{3}$, presence of a garage and floor number. The house type is categorised as detached, semidetached/terraced and flat. The sale price of each house is given in $€$ s converted from drachmas. A quarterly consumer price index for the housing sector in Greece (OECD, 2006) was used to adjust the prices to 2001 levels.

The full address of each house sale was available, allowing the assignment of geographical coordinates to each house (with 20 meters accuracy or better) and the derivation of further geographical information through GIS modelling. Certain local amenities have been shown to affect house prices (Frankel, 1988; Bateman et al., 2001). We located 445 such amenities in the area and used the specific coordinates to estimate the crow fly distance between each house and the nearest church, public service facility, sport facility, hospital or health centre,

\footnotetext{
1 "Property AE", was an established real estate consulting firm at the time, specialised in housing market studies and connected with local real estate agents and the National Bank of Greece, published the "real estate news" magazine.

${ }^{2}$ Excluding balconies, gardens and sheds

${ }^{3}$ Excluding bathrooms, kitchens and storage rooms
} 
plaza, super market and school. The premium of a seaside location is controlled for by introducing a dummy for houses within 300 meters of the coastline ${ }^{4}$.

Digital maps ${ }^{5}$ and local road network data were acquired. The road distance from each house to the Airport entrance was then estimated, since access to the airport is usually by car or public transport rather than on foot, as would be the case for many other local amenities in close proximity. These data also allowed the estimation of the distance to the closest point of a main road for each house. This is expected to account for better accessibility, but also for additional road noise, for which we do not have any other available information.

Figure 1 illustrates all the available geographical information for the study area, including the location of each house sale, the road network, the main roads, the airport entrance, the coast line and the amenities in the area.

Table 1 provides the details of all available data. Most of the data refer to newly constructed properties; $73 \%$ were built within 5 years of the sale and $83 \%$ are flats. This is due to the high development rate of the local housing market during the study period. The market was in the process of replacing older, lower quality and low rise houses (detached/semidetached) with high rise flat complexes. We are confident that our data sample reflects the situation in the local housing market during the study period. This was also supported by the interviews conducted with local real estate agents and housing market professionals in 2004. We were unable to confirm this from official data sources in Greece, since appropriate data were simply not available for the area and study period.

Looking at the spatial distribution in figure 1 the data provide good coverage for all the areas (the road network indicates the inhabited part of the map), with coastal areas having the highest observation density. The estimation of aircraft noise exposure data is discussed in section 5 .

\footnotetext{
${ }^{4}$ We did not use a continuous distance to the coast variable, because it did not capture the amenity of residing near the sea for observations further inland. Instead the inclusion of this variable introduced collinearity in the models. We tested a range of dummy variables and the 300 meter dummy provided best statistical fit.

${ }^{5}$ The company Eratosthenes S.A. provided digital maps of the road network in the study area
} 
Figure 1: The geographical features of the study area and the location of each house sale

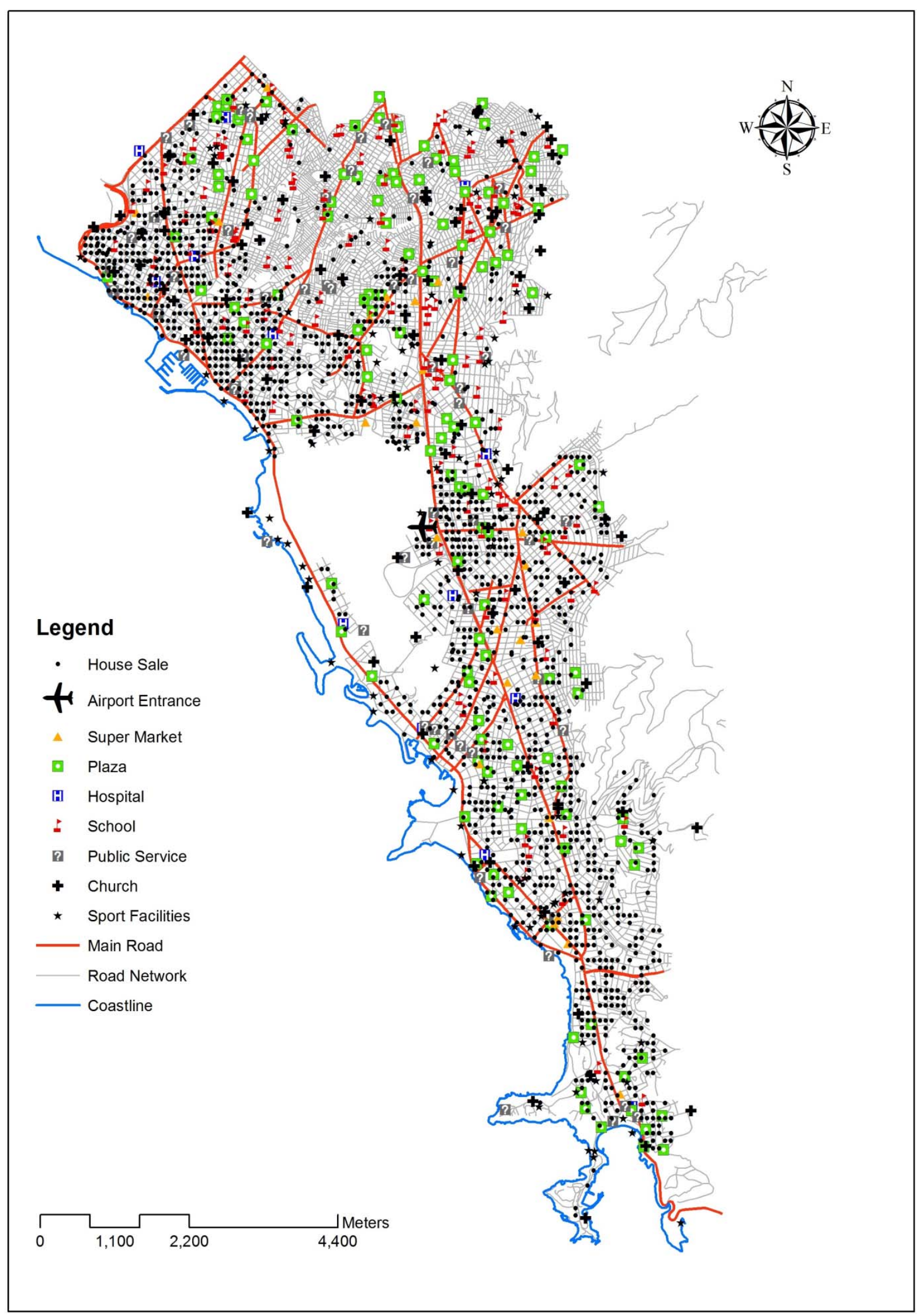


Table 1: Data description

\begin{tabular}{|c|c|c|c|c|c|}
\hline Variable name & Description & Mean & S.D. & Min & Max \\
\hline price & Mean house sale price in $€$ in 2001 levels & 176605 & 111798 & 26412 & 1027146 \\
\hline Ln_price & Natural Logarthim of the house price & 12.09 & 0.61 & 9.9 & 14 \\
\hline room_no & Number of rooms & 4.31 & 1.48 & 1 & 9 \\
\hline built_per & $\begin{array}{l}\text { Time elapsed in years since construction of } \\
\text { building }\end{array}$ & 3.86 & 3.63 & 0 & 20 \\
\hline floor_no & floor number & 2.42 & 1.58 & 0 & 8 \\
\hline Air_noise & The aircraft noise in decibels, 90 day $\mathrm{L}_{\mathrm{den}}$ & 61.96 & 7.06 & 38 & 82 \\
\hline $\mathrm{L}_{\mathrm{den} \_}$tot & Algebraic sum of aircraft and background noise & 63.59 & 5.26 & 55 & 82 \\
\hline sq meters & Square meters of the house floor & 118.1 & 72.2 & 22 & 500 \\
\hline room1_2 & Dummy equals 1 when 1 or 2 rooms & 0.09 & 0.29 & 0 & 1 \\
\hline room 3 & Dummy equals 1 when 3 rooms & 0.17 & 0.37 & 0 & 1 \\
\hline room4 & Dummy equals 1 when 4 rooms & 0.41 & 0.49 & 0 & 1 \\
\hline room5 & Dummy equals 1 when 5 rooms & 0.10 & 0.30 & 0 & 1 \\
\hline room6 & Dummy equals 1 when 6 rooms & 0.07 & 0.25 & 0 & 1 \\
\hline room7 & Dummy equals 1 when 7 rooms or over & 0.14 & 0.35 & 0 & 1 \\
\hline House $>10 y r$ & Dummy equals 1 when house built over 10 years & 0.11 & 0.31 & 0 & 1 \\
\hline House 6-9yr & $\begin{array}{l}\text { Dummy equals } 1 \text { when house built between } 6 \\
\text { and } 9 \text { years ago }\end{array}$ & 0.15 & 0.36 & 0 & 1 \\
\hline H_Age_B & $\begin{array}{l}\text { Dummy equals } 1 \text { when the house age is below } 5 \\
\text { years or unknown }\end{array}$ & 0.74 & 0.44 & 0 & 1 \\
\hline floors_7-8 & Dummy equals 1 when floor number 7 to 8 & 0.01 & 0.11 & 0 & 1 \\
\hline floors_4-6 & Dummy equals 1 when floor number 4 to 6 & 0.19 & 0.39 & 0 & 1 \\
\hline floors $<4$ & $\begin{array}{l}\text { Dummy equals } 1 \text { when floor number is below } 4 \\
\text { or unknown }\end{array}$ & 0.80 & 0.40 & 0 & 1 \\
\hline detached & Dummy equals 1 when detached house type & 0.09 & 0.28 & 0 & 1 \\
\hline semidetached & Dummy equals 1 when semidetached house & 0.08 & 0.28 & 0 & 1 \\
\hline flat & Dummy equals 1 when flat & 0.83 & 0.35 & 0 & 1 \\
\hline garage & Dummy equals 1 when private garage available & 0.41 & 0.49 & 0 & 1 \\
\hline non_coastal & $\begin{array}{l}\text { Dummy equals } 1 \text { when house located in the } \\
\text { non-coastal area }\end{array}$ & 0.10 & 0.30 & 0 & 1 \\
\hline Coastal_area & $\begin{array}{l}\text { Dummy equals } 1 \text { when house located in the } \\
\text { coastal area }\end{array}$ & 0.90 & 0.37 & 0 & 1 \\
\hline d_sports & $\begin{array}{l}\text { Distance in meters to the nearest outdoor } \\
\text { sporting facility }\end{array}$ & 557 & 333 & 18 & 1899 \\
\hline d_public_serv & $\begin{array}{l}\text { Distance in meters to the nearest public service } \\
\text { building }\end{array}$ & 571 & 366 & 18 & 1999 \\
\hline d_plaza & Distance in meters to the nearest plaza & 354 & 206 & 9 & 1363 \\
\hline d_school & Distance in meters to the nearest school & 401 & 294 & 14 & 1977 \\
\hline d_supermarket & Distance in meters to the nearest supermarket & 757 & 459 & 9 & 2863 \\
\hline d_church & Distance in meters to the nearest church & 429 & 232 & 11 & 1632 \\
\hline d_health & $\begin{array}{l}\text { Distance in meters to the nearest hospital or } \\
\text { health centre }\end{array}$ & 969 & 529 & 24 & 2637 \\
\hline d_main_rd & $\begin{array}{l}\text { Distance in meters to the closest point of a main } \\
\text { road }\end{array}$ & 221 & 211 & 0 & 1478 \\
\hline d_air_rd & $\begin{array}{l}\text { Drive distance in meters to the airport entrance } \\
\text { through the road network }\end{array}$ & 5351 & 2378 & 201 & 11233 \\
\hline d_air_4km & As above, truncated to 4000 meters & 3526 & 938 & 201 & 4000 \\
\hline Akto_300m & $\begin{array}{l}\text { Dummy equals } 1 \text { when the house is located } \\
\text { within } 300 \mathrm{~m} \text { from the coastline }\end{array}$ & 0.13 & 0.34 & 0 & 1 \\
\hline y95q1-y00q4 & \multicolumn{5}{|c|}{ Dummies for each quarter from the 1 st quarter of 1995 to 4 th quarter of $2000^{\wedge}$} \\
\hline
\end{tabular}

$\wedge$ Includes a few observations from the beginning of 2001 


\section{Spatial dependence in HP and temporal ordering}

Independence of residuals is an essential assumption in the econometric estimation of HP models using ordinary least squares (OLS) regressions. When the assumption of independence between observations across space is violated, this is termed spatial dependence. This leads to inefficient estimators and biased standard error estimates, affecting confidence levels for the coefficients and predicted values (Anselin, 2003; Nelson, 2008), rendering OLS inappropriate for models containing spatial dependence.

In the housing market, spatially dependent errors are seen to arise for either of the following two reasons (Anselin, 2003; Nelson, 2008). Firstly, the price of a house is not only affected by its attributes but also by the prices of houses in close proximity. In this case a spatial lag model (SLM) is appropriate, shown in Eq. 3, where spatially lagged price observations of neighbouring houses are included as an independent variable. In the second case, the residuals contain systematic spatial information that is not captured by the regression model, requiring what is termed a Spatial Error Model (SEM), illustrated in Eq. 5. This is appropriate when houses share common amenities that have a spatial pattern and these amenities cannot be controlled for (Anselin, 2003; Nelson, 2008).

The structural form of the SLM is:

$P=\zeta W P+X b+\varepsilon, \quad \varepsilon \sim N\left(0, \sigma^{2} I\right)$

and its reduced form is:

$P=[I-\zeta W]^{-1} X b+[I-\zeta W]^{-1} \varepsilon$

The structural form of SEM is:

$P=X b+\varepsilon$

Where $\varepsilon=\lambda W \varepsilon+u$. The reduced form of SEM is given by:

$P=X b+[I-\lambda W]^{-1} u, u \sim N\left(0, \sigma^{2} I\right)$,

Where $P$ is a vector of the house prices, $X$ is a matrix of housing characteristics and $b$ is a vector of the coefficients. The spatial correlation structure between observations is given by the spatial weight matrix W. $\zeta$ or $\lambda$ are the spatial dependence coefficients that are estimated in the modelling process. SLM and SEM are reduced to OLS models, if $\zeta$ or $\lambda$ respectively are equal to zero. 
The presence of a lagged price variable in SLM denotes that the total increase in value due to a change in an attribute can be decomposed into a direct and an indirect effect. The latter occurs when the increased value of the property in question raises the value of neighbouring properties that in turn raise the value of the property in question further (Andersson et al., 2010). Eq. 4 demonstrates that the marginal implicit price in SLM for attribute $\omega$ is not given by $b_{\omega}$, but by $b_{\omega}[I-\zeta W]^{-1}$ (Kim et al., 2003), where $[I-\zeta W]^{-1}$ is termed spatial multiplier. Some HP studies that use SLM disregard the spatial multiplier effect (Chalermpong, 2010) or assume the issue away (Andersson et al., 2010). Cohen and Coughlin (2008) estimate spatial multiplier effects for noise and discuss the indirect spatial effects. This is not an issue in SEM.

\subsection{Spatial weight specification}

Spatial weights are usually based on distance or contiguity. In defining contiguity weights, areas (polygons) adjacent with the targeted area (polygon) of the house sale are assigned a weight of 1 in the weighting matrix, and all other areas a weight of 0 . This approach reduces the probability overestimation of spatial correlation, where everything is correlated with everything else (Conway et al., 2010) but does not address temporal ordering.

Imposing contiguity weights introduces unverifiable assumptions about the structure and the interactions of the housing market and urban space. One needs to specify units, within which the observations behave in the same way and adjacent units to which the interactions are limited. Submarket effects are not always distributed spatially and spatial sub-markets do not often coincide with administrative areas (Watkins, 2001, Bateman et al., 2004). Rather than being based exclusively on the similarity of property characteristics or geographical contiguity, the dimensions of housing submarkets are determined by both spatial and structural factors simultaneously (Watkins, 2001) and socioeconomic characteristics of the local population (Bateman et al., 2004).

Therefore, we prefer distance based spatial weights for HP models. We specify the weights as the inverse distance between house sale observations following Can and Megbolugbe (1997). This accounts for the diminishing effect of house sales prices that are further from each other. 
The spatial weights are in the form of a square $n \times n$ matrix $W$. We specify three distance based spatial weight matrices $\mathrm{W}_{\alpha}, \mathrm{W}_{\beta}$ and $\mathrm{W}_{\gamma}$. Each element $w_{i j}$ in matrix $\mathrm{W}_{\alpha}$ is given by:

$w_{i j}=\left\{\begin{array}{c}\frac{1}{d_{i j}} \text { if } \mathrm{i} \neq \mathrm{j} \\ 0 \text { if } \mathrm{i}=\mathrm{j}\end{array}\right.$

Where $d_{i j}$ is simply the inverse Euclidean distance between house $i$ and house $j . \mathrm{W}_{\alpha}$ is a symmetric square matrix with the main diagonal being zero (the effect of each sale price to itself). This is similar to the common approach in the literature, when distance weights are employed and contains the temporal ordering inconsistency.

One important consideration in specifying spatial weight matrices is to avoid overestimation of spatial dependence, where each observation is spatially connected to every other observation and vice versa and other factors are underestimated. Most studies that employ distance based weights introduce an arbitrary cut-off point, after which house prices are not assumed to affect each other within an urban structure. For example, Andersson et al. (2010) present two models with cut off points at $4 \mathrm{~km}$ and $10 \mathrm{~km}$. Kim et al. (2003) consider as neighbours all housing units in the same sub-district as well as all units in districts that have their centroid within $4 \mathrm{~km}$. Bateman et al. (2004) introduce much lower cut-off points of about $0.25 \mathrm{~km}$ for various sub-market HP models. Similarly Chalermpong (2010) and Salvi (2008) use a $0.3 \mathrm{~km}$ cut-off point. The temporal ordering inconsistency is effectively a case of overestimating spatial dependence, mistaking a uni-directional relationship for two way interdependence. In addressing the temporal ordering inconsistency, we account for part at least of any spatial dependence overestimation, as is discussed below.

Looking the aircraft noise spatial HP literature, Dekkers and Van der Straaten, (2009), Theebe (2004), Salvi (2008) and Chalermpong (2010) specify their spatial weight matrices in a way that includes the temporal ordering inconsistency. Cohen and Coughlin (2008) and Bateman et al. (2004) assume that the house sale observations cover a single period, a year. If no more specific information about sale dates is available, they would not be able to impose any temporal ordering in their data. However, a year is too long a period to be considered as a simultaneous sale for all the data (Pryce and Gibb, 2006; Zuelke, 1987; White and Watkins, 2004). Even if they do not have the information to address temporal ordering, it is still in the 
data, since they employ symmetric spatial weight matrices that assume interdependence between the sale prices. Hence, there is still overestimation of spatial dependence due to temporal ordering, even if some overestimation is dampened through arbitrary cut-off points.

As our case study area is a relatively small geographical part of Athens where everything affects everything else, albeit to a small degree, we do not specify any distance cut-off point. There is no theoretical reason but only methodological necessity/convenience. However, the inverse distance specification employed here accounts for any diminishing effect of house sales prices that are further from each other. To address the temporal ordering inconsistency that is present in $\mathrm{W}_{\alpha}$, we specify matrix $\mathrm{W}_{\beta}$ with each element $w_{i j}$ given by:

$w_{i j}=\left\{\begin{array}{c}\frac{1}{d_{i j}} \text { if } t_{i}>t_{j} \text { and } \mathrm{i} \neq \mathrm{j} \\ 0 \text { if } t_{i} \leq t_{j} \text { and } / \text { or } \mathrm{i}=\mathrm{j}\end{array}\right.$

Where $t_{i}$ and $t_{j}$ is the number of days elapsed since the first observation in the dataset and the sale of houses $i$ and $j$ respectively. When the data are ordered from the "furthest in the past" to the latest house sale, $\mathrm{W}_{\beta}$ becomes a lower triangle square matrix, with all the values of the upper triangle being zero. Only sales in the past affect subsequent sales and not vice versa. Thus $\mathrm{W}_{\alpha}$ contains double the information of $\mathrm{W}_{\beta}$, even though this information is the product of the paradoxical assumption of sales prices being affected by sales that have not yet taken place. We expect that due to this extra information $\mathrm{W}_{\alpha}$ will produce better fitting models than $\mathrm{W}_{\beta}$, overestimating spatial dependence. Hence, overall goodness of fit measures cannot provide guidance to choosing the preferred model in this context; only theoretical considerations can help.

One of these theoretical considerations is the assumption in $\mathrm{W}_{\beta}$ that sale prices further in the past should affect a current sale price to the same extent as more recent sale prices. An allowance for temporal distance, maybe in the form of a time decay factor, may therefore be an appropriate addition to the distance weights that specify the connection in space between the observations. In the current model form it is not computationally feasible to estimate a time decay function on the top of the estimated spatial parameters. The time decay factor must be specified a priori. Hence, we look at the housing economics literature for clues as to what time frame may be appropriate when considering a decay factor for the spatial weights. 
Pryce and Gibb (2006) show that about $80 \%$ of the properties on sale in Strathclyde are sold within 1 quarter and about $90 \%$ of the properties are sold within 2 quarters. Zuelke (1987) find the average market duration of a house on sale in Florida being about 4 months and less than 6 months for the $82 \%$ of their sample. White and Watkins (2004) determine that the vast majority of the properties on sale in Aberdeen were sold within 95 days. We assume that price setting behaviour of the seller is mostly affected by the price levels at the time and the same goes for the buyer, when he is doing market research.

The time-on-the-market studies above indicate that the time scale, in which house market participants are most exposed to effects from past house sales, is within a quarter of the sale. Hence, this may be the most appropriate time frame in which to analyse these effects. We further assume that the effect on subsequent house prices from past sales is reducing nonlinearly with passing time. Sales far in the past can be seen as providing a background in the market. We combine these insights to specify a new weight matrix. Each matrix element of inverse Euclidean distance between two observations is divided by the number of quarters between the two sales. Thus our approach diverges from Can and Megbolugbe (1997), who include in their preferred spatial weight specification all prior sales that occurred within a $3 \mathrm{~km}$ of a current transaction and only within the prior two quarters. This way they are setting cut off points in both space and time. As discussed above, we do not see any reason to set distance cut off points in this context and the effects of past sales to subsequent house prices is dampened after two quarters instead of being assumed zero.

More formally, to take account of time decay we specify the weight matrix $\mathrm{W}_{\gamma}$, by multiplying each element $w_{i j}$ in $\mathrm{W}_{\beta}$ by the time decay rate $r_{i j}$ :

$r_{i j}=\left\{\begin{array}{c}\frac{1}{q_{i}-q_{j}} \text { if } \mathrm{i} \neq \mathrm{j} \\ 1 \quad \text { if } \mathrm{i}=\mathrm{j}\end{array}\right.$

Where $q_{i}$ and $q_{j}$ are the quarters during which houses $\mathrm{i}$ and $\mathrm{j}$ were sold respectively, with $q$ taking values $1,2, \ldots m$, where $m$ is the latest quarter in the dataset. 
This implies that the bigger difference between the quarters of any two house sales, the less the spatial weight in the modelling. For example if house $j$ was sold 2 years before house $i$ it loses $87.5 \%$ of the weight it would have if the sales took place in the same quarter. Houses sold in the same quarter or within a quarter of each other are weighted by the inverse distance without any effect from $r_{i j}$. The feature of $\mathrm{W}_{\beta}$, where sale prices cannot affect the prices of preceding house sales is kept in $\mathrm{W}_{\gamma}$. Hence, negative values of $r_{i j}$ are unimportant, since they multiply zeros in upper triangle part of the matrix $\mathrm{W}_{\beta}$.

\section{Aircraft Noise}

\subsection{The treatment of noise in the spatial HP literature}

Here we consider the treatment of aircraft noise in the published studies that apply spatial HP models to aircraft noise valuation. Issues include the use of continuous or banded data, the use of cut-off or threshold values and the treatment of background noise.

Theebe (2004), Cohen and Coughlin (2008) and Chalermpong (2010) use a dummy variable specification for noise, producing statistically significant estimates only above $65 \mathrm{dBA}$, $70 \mathrm{dBA}$ and $70-75 \mathrm{dBA}^{6}$ respectively, all of which are very high levels of noise exposure. Chalermpong (2010) also has a serious data constraint ${ }^{7}$, which might affect the aircraft noise estimates. Theebe (2004) transformed continuous noise data to $5 \mathrm{dBA}$ noise bands. We consider dummy specifications (constructed from noise contours/bands or continuous data) as an inferior approach to continuous aircraft noise exposure data. Dummy specifications make no distinction between properties within a contour. The noise banding also imposes untestable assumptions about functional form of noise depreciation and thresholds.

Regarding the studies that employed a continuous aircraft noise variable, Salvi (2008) produced a statistically significant estimate of $0.97 \%$ aircraft noise depreciation on house prices for $1 \mathrm{dBA}$ increase, which is rather on the high side of the HP literature. A reasonable

\footnotetext{
${ }^{6}$ Chalermpong (2010) uses 30-35 and 35-40 Noise Exposure Forecast (NEF) contours that closely correspond to 65-70 and 70-75 dBA of $\mathrm{L}_{\mathrm{dn}}$ metric respectively. $\mathrm{L}_{\mathrm{dn}}$ is the equivalent continuous sound pressure level over a fixed time period (Leq) where the night values $(22: 00-06: 00)$ are weighted by the addition of $10 \mathrm{dBA}$.

${ }^{7}$ It is stated that most of the 37,591 observation had identical characteristics and were sold at the same price. Therefore, the dataset was restricted to only 384 observations for the HP modelling. It is not made clear how these 384 observations were selected, since 554 observations of the extended dataset were in the 35-40 NEF contour and 1784 in the 30-35 NEF contour.
} 
threshold of $50 \mathrm{dBA}$ was employed for both aircraft and road traffic noise. Bateman et al. (2004) could not attribute any statistically significant effect to aircraft noise, using a common cut off point across modes of 55dBA below which it was assumed that transport noise was indistinguishable from ambient noise. Dekkers and Van der Straaten (2009) report a model with thresholds that vary by the noise source, $45 \mathrm{dBA}$ for air traffic, $55 \mathrm{dBA}$ for road and 60 dBA for rail, recovering a statistically significant effect for aircraft noise of $0.77 \%$ depreciation per $\mathrm{dBA}$ on house prices. The authors noted that threshold selection influenced their aircraft noise value estimates, with the coefficient becoming insignificant at threshold levels equal to or above 50dBA. They do not report the effects of changing the road and rail noise threshold levels.

The use of thresholds is problematic, especially the explicit assumption that below a preselected level aircraft noise does not impact on values. The inclusion of noise from other transport modes, as Salvi (2008) and Dekkers and Van der Straaten (2009) do, is an attempt to allow for background noise. However, the use of different thresholds in Dekkers and Van der Straaten (2009), whilst reflecting evidence in the annoyance literature is questionable in this context. They are effectively assuming that road traffic noise will not impact on welfare until it is $55 \mathrm{dBA}$, whereas aircraft noise will do so at half the intensity, $45 \mathrm{dBA}$.

Nonlinear econometric specifications of the noise variable may arbitrarily impose a predetermined functional form, as a concave function in Andersson et al. (2010). Such approaches also require estimation of additional parameter(s) in models that cannot simultaneously account for spatial dependence (Kim et al., 2003). Hence, such specifications are not employed in this paper.

\subsection{Treatment of aircraft and background noise in this study}

The physical aircraft noise estimates were supplied by the European Organisation for the Safety of Air Navigation (EUROCONTROL), who have complete data on flight paths and aircraft movements for Hellenikon Airport. Radar data were employed to derive more accurate aircraft approaches to the airport and the Integrated Noise Model (Federal Aviation Administration, 2003) was employed for the aircraft noise modelling. The consistency of the modelled data with actual noise measurements was confirmed by EUROCONTROL. A set of 
coordinates for each house sale was provided to EUROCONTROL and they supplied an estimate of the aircraft noise exposure for the specific coordinates.

The noise exposure data is in the $\mathrm{L}_{\mathrm{den}}{ }^{8}$ noise metric, which is seen as appropriate for aircraft noise in the EU (EC, 2002) and is commonly used in HP studies valuing noise (Dekkers and Van der Straaten, 2010; Rich and Nielsen, 2004; Baranzini and Ramirez, 2005). Miedema et al. (2000) investigated which noise metrics best predict annoyance from aircraft noise and supported the use of weighted noise metrics, such as $\mathrm{L}_{\mathrm{den}}$, instead of $\mathrm{L}_{\mathrm{eq}}$ in this context.

The decibel value provided represents the average value of the 90 day period preceding the house sale. This is to prevent the decibel value reflecting daily, weekly or monthly peaks that can be misleading for this kind of analysis. This averaged value is expected to better reflect the effect of aircraft noise exposure on housing market actors prior to house purchase.

The basic descriptive statistics for aircraft noise exposure are found in Table 1 under the "Air_noise" variable. Figure 2 visually illustrates this exposure on our housing data using 5 decibel contours. There is much variation in aircraft noise exposure across the study area reaching a maximum of $82 \mathrm{dBA}$. Residents in the municipality of Alimou (north-northwest of the airport) were exposed to by far the highest noise levels, as noted elsewhere in the literature (Yang and Kang, 2005; Charalampakis, 1980).

Clearly we wish to take account of background noise pollution from road traffic and other sources. Unfortunately, no data were available on other sources of noise pollution such as road traffic. From previous studies of the noise situation in Athens (Nicol and Wilson, 2004; Yang and Kang, 2005), it can be deduced that a 55dBA value for background noise would be a reasonable approximation. In addition we used distance to a major road as a proxy for higher exposure to traffic noise.

\footnotetext{
${ }^{8}$ Equivalent continuous sound pressure level over a fixed time period $\left(\mathrm{L}_{\mathrm{eq}}\right)$, where the evening values $(18: 00$ 22:00) are weighted by the addition of $5 \mathrm{dBA}$ (A-weighted decibel), and the night values (22:00 - 06:00) are weighted by the addition of $10 \mathrm{dBA}$
} 
Figure 2: Aircraft noise contours

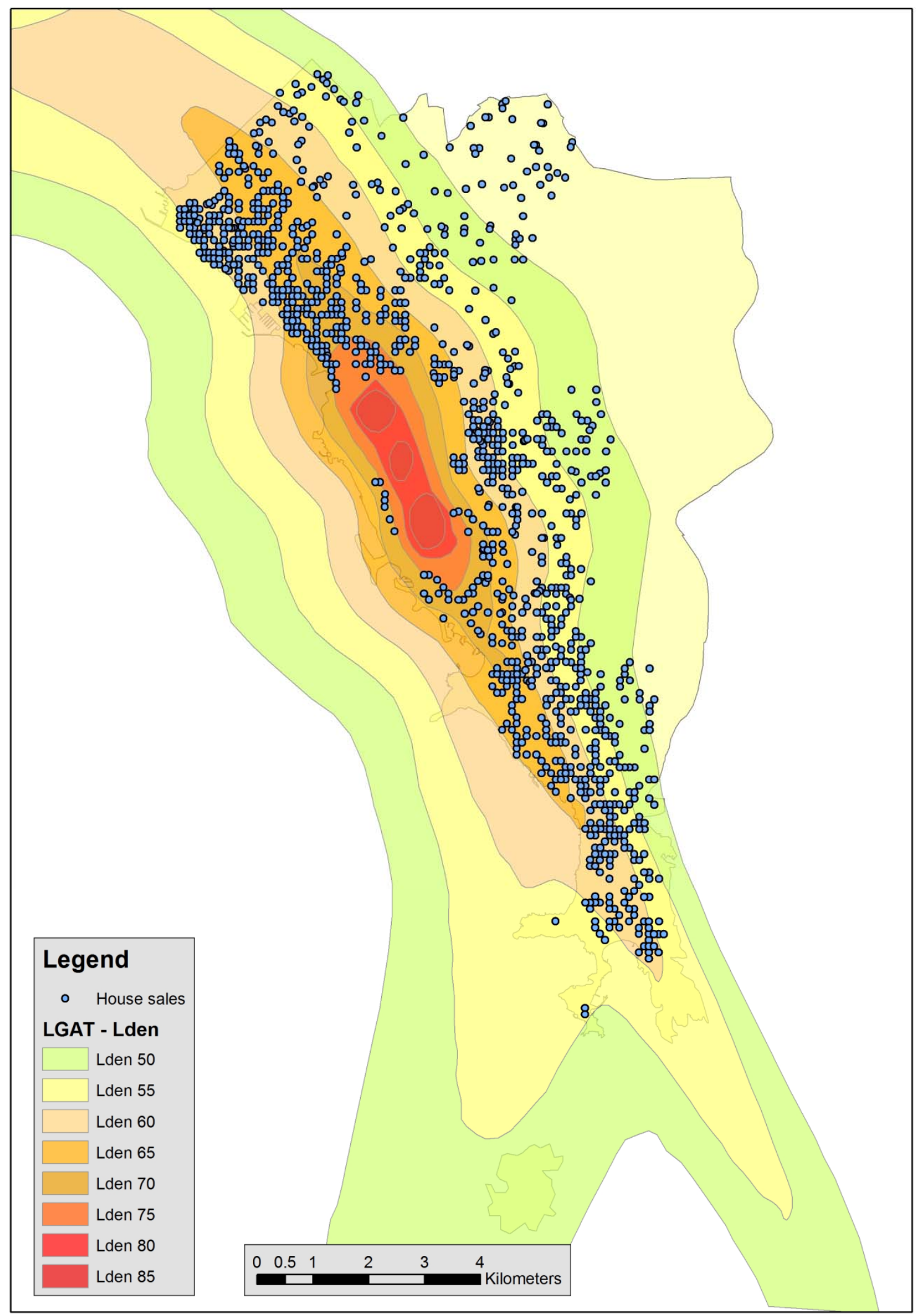


We attempt to capture the effect of aircraft noise on the housing market above the general noise level in the area, even if aircraft noise effects are very low when dominated by other noise sources. Following Andersson et al. (2010) and Thanos et al. (2011), the aircraft noise level $\left(\gamma_{a}\right)$ and the assumed background noise level $\left(\gamma_{b}\right)$ are combined in a total noise level $\left(\gamma_{t}\right)$ that is given by:

$\gamma_{t}\left(\gamma_{a}, \gamma_{b}\right)=10 L O G_{10}\left(10^{\frac{\gamma_{a}}{10}}+10^{\frac{\gamma_{b}}{10}}\right)$

The $\gamma_{t}$ is used in HP models. If $\gamma_{a}$ is dominant, $\gamma_{b}$ will have an almost negligible effect on the total noise level and vice versa $\left(\gamma_{a} \oplus \gamma_{b} \approx \gamma_{a}\right.$ if $\left.\gamma_{a} \gg \gamma_{b}\right)$. This analysis can be considered a step forward from studies that simply examine variations in aircraft noise above a prespecified cut off point. Even low levels of aircraft noise are included in the analysis that would otherwise have been below a $55 \mathrm{dBA}$ cut off point; for example $51 \mathrm{dBA}$ aircraft noise and $55 \mathrm{dBA}$ background produce a total noise level of $56.46 \mathrm{dBA}$.

Variable " $\mathrm{L}_{\text {den_t }}$ tot" in Table 1 provides the descriptive statistics for $\gamma_{t}$. The difference between the mean noise total $(63.59 \mathrm{dBA})$ and the mean of only aircraft noise $(61.96 \mathrm{dBA})$ is $1.63 \mathrm{dBA}$, indicating that aircraft noise dominates the sound-scape of the case study area. Thus we have a continuous aircraft noise variable that explicitly includes an allowance, albeit crude, for background noise, avoiding any need for the imposition of artificial thresholds.

\section{The HP Modelling}

Bateman et al. (2004) attributed their failure to produce statistically significant estimates to aircraft noise being less localised than other sources and thus subsumed in their treatment of spatial effects. In section 4 it was shown that the temporal ordering inconsistency is a case of overestimating spatial dependence in HP models. In the literature spatial dependence overestimation is usually dampened through arbitrary cut-off points, specification of which may well be affected by the temporal ordering inconsistency. We posit that the temporal ordering inconsistency is at least partly responsible for subsuming aircraft noise estimates. This is explored further in this section. 


\subsection{Methodological Considerations}

The form of the hedonic price function is not strictly prescribed by economic theory. Given that the Box-Cox specification is not readily implemented in the presence of spatial dependence (Kim et al., 2003), a semi-log specification is selected. It is the most widely used in the literature, providing an excellent goodness-of-fit to our data. In the semi-log specification the regression coefficient for aircraft noise is the price depreciation for a $1 \mathrm{dBA}$ increase, taking the form of $\mathrm{NDI}^{9}$ when multiplied by 100 .

We included in the HP models most of the information available to us, presented in Table 1. The standard characteristics were included such as floor size, year and quarter of the sale, house type and private garage. However, there were some minor issues that needed to be addressed. Floor number, room number and house age contain between about 150 missing or inapplicable observations, thus we constructed the dummy variables seen in Table 1 to address this issue. The inclusion of room number as continuous variable also introduced collinearity to the models, thus the 4 room category is used as the base with all other values are included in the model as dummies. Given the housing stock on sale is relatively new, we constructed two categories for house age that might have enough observations to produce statistically significant results, between 6 and 9 years and over 10 years, with the base being less than 5 years. Since flat is the dominant house type in Athens, higher floor numbers are considered advantageous due to better views, especially in areas near the sea, such as our study area. Hence, we specified two dummy variables that account for this effect, floor number being between 4 and 6 or between 7 and 8, with floor number below 3 being the base category. More detailed categorisation of the floor number did not produce statistically significant coefficients. As for the quarterly dummies, the last quarter in our data $\left(4^{\text {th }}\right.$ quarter $2000)$ is the base category.

The wider area around the airport is also called the "south suburbs" of Athens and is a distinct housing submarket attracting a higher premium than more central locations and most other fringe areas. The structure and geography of Athens metropolitan area, especially of its housing market, does not conform to a concentric zone model (Allen et al., 2004; Fellmann et al. 2003), where distance to the centre an essential feature. In our models, distance to the

\footnotetext{
${ }^{9} N D I=(\partial P / \partial \gamma) \times(1 / P) \times 100=\beta \times 100$ where $\beta$ is the coefficient of aircraft noise variable $\gamma$
} 
Athens centre is dropped as it introduces collinearity, affecting many of the other distance variables and aircraft noise. This is due to the geography of the local area that is a narrow strip of inhabited land pointing to the centre of Athens, especially south-southeast from the Airport (see Figure 1). Instead, we control for the high density area closer to the centre by introducing a dummy for the non-coastal area directly north from the airport (see Figure 1), where houses are expected to command significantly lower premiums.

All the other geographical information was included in the HP models. The distance to the airport did not produce statistically significant coefficients when introduced in the models. The positive externalities of proximity to an airport may not affect houses that are further away, truncating the distance to the airport to $4 \mathrm{~km}$ proved the most effective approach.

An important methodological issue is the selection of either SLM or SEM. We adopt the approach of performing a battery of specification tests on the OLS residuals of the HP regression after using the appropriate spatial weight matrix. The appropriate tests are Moran's I for detecting spatial dependence and locally robust variations of the classical Lagrange Multiplier test for selecting the model form (Anselin, 1988; Anselin et al., 1996; Florax et al., 2003; Franzese and Hays, 2008).

Table 2 presents these tests, where the null hypothesis in Moran's I test of no spatial dependence is rejected in all models. However, the tests for selecting SLM or SEM are more interesting, since the temporal ordering inconsistency seems to affect model selection. Testing the full weight matrix $\left(\mathrm{W}_{\alpha}\right)$ that includes temporal ordering inconsistencies shows both spatial lag and error to be statistically significant, which would require arbitrarily selecting one of the two. Interestingly this was also the finding of Chalermpong (2010) and Dekkers and Van der Straaten (2009) whose tests for both spatial lag and error are statistically significant in models that contain temporal ordering inconsistencies.

When the temporal ordering inconsistency is removed in weight matrix $\mathrm{W}_{\beta}$, the robust spatial lag test becomes insignificant, whereas the test for spatial error is still highly significant. This pattern is even more prominent in the weight matrix $\mathrm{W}_{\gamma}$ that includes time decay. Hence, we select the spatial error model. One interpretation of this result is that, in some cases at least, the temporal ordering inconsistency seems to introduce a spatial pattern that passes for the 
effects of a spatially lagged variable. In this context this would be house prices directly affecting neighbouring prices, instead of the correct common exposure pattern.

Table 2: Spatial Dependence diagnostics

\begin{tabular}{|c|c|c|c|c|c|c|}
\hline & \multicolumn{2}{|c|}{$\mathrm{W}_{\alpha}:$ Full Weight } & \multicolumn{2}{|c|}{$\mathrm{W}_{\beta}$ : Trill^ ${ }^{\wedge}$ Weight } & \multicolumn{2}{|c|}{$\mathrm{W}_{\gamma}$ : Time Decay^ } \\
\hline & Statistic & p-value & Statistic & p-value & Statistic & $\mathrm{p}$-value \\
\hline Moran's I & 41.919 & 0 & 25.577 & 0 & 23.311 & 0 \\
\hline Lagrange multiplier SEM & 780.366 & 0 & 260.855 & 0 & 234.812 & 0 \\
\hline $\begin{array}{l}\text { Robust Lagrange multiplier } \\
\text { SEM }\end{array}$ & 690.08 & 0 & 254.717 & 0 & 228.561 & 0 \\
\hline Lagrange multiplier SLM & 253.685 & 0 & 9.305 & 0.002 & 8.76 & 0.003 \\
\hline $\begin{array}{l}\text { Robust Lagrange multiplier } \\
\text { SLM }\end{array}$ & 116.27 & 0 & 3.167 & 0.075 & 2.509 & 0.113 \\
\hline
\end{tabular}

${ }^{\wedge}$ Lower triangle matrix

As to the selection of an estimator, Maximum Likelihood (ML) estimation requires the assumption of normality (Cohen and Coughlin, 2008; Kim et al., 2003). The Jarque-Bera test (Jarque and Bera, 1987) cannot reject at the $99 \%$ level the null hypothesis of normality ${ }^{10}$ in the OLS residuals. Therefore, we use the ML estimator of Barry and Pace (1999) adapted and discussed in Franzese and Hays (2008), pointing out that the strictly lower triangular nature of $\mathrm{W}_{\beta}$ and $\mathrm{W}_{\gamma}$ avoids the need to compute the determinant of a general matrix.

\subsection{The HP Models Results}

The HP model results are presented in Appendix 1. Looking at the OLS model, the fit to the data is excellent, explaining almost $87 \%$ of the variation. All the coefficients across the four models are of the expected sign and most are statistically significant at the $95 \%$ level. In all models, higher floor flats command a premium, as do detached houses and private garages. Conversely, houses in the non-coastal area or with lower room number are penalised. As expected, the square meters of the floor space has a very significant positive effect on house prices in our models. Being closer to schools, churches, the airport entrance and within 300 meters of the coastline positively affects prices. The distance to main roads coefficient is positive, possibly capturing accessibility advantages rather than traffic noise exposure. The price is negatively affected by proximity to plazas, which could be due to increased noise from human traffic and nightlife, and proximity to sport facilities, since these are mostly

\footnotetext{
${ }^{10}$ Jarque-Bera statistic: 2.7339 (critical value: 5.9550), p: 0.24.
} 
outdoor basketball courts and football grounds and tend to be on the fringe of the urban area. House age, proximity to public service buildings and hospitals do not have a statistically significant effect.

The aircraft noise coefficient in the OLS model produces a NDI of 0.646 , which is in line with the HP literature (Nelson, 2004; Wadud, 2010). The most striking change between the OLS and the ML1 model, which includes the temporal ordering inconsistency, is the fact that the aircraft noise coefficient is not statistically significant. This demonstrates that the temporal ordering inconsistency introduces overestimation of spatial dependence in a pattern that directly affects aircraft noise estimates. This is further supported by the results of ML2 and ML3 that correct for the temporal ordering inconsistency and produce a statistically significant aircraft noise coefficient of higher magnitude compared to ML1.

There is also a substantial reduction in the magnitudes of most of the distance effects in ML1 compared to OLS. The coefficients of "within 300 meters of the coastline", "distance to church and main roads" lose statistical significance at the 95\% level. In ML2 and ML3 distance effect estimates almost return to the OLS levels, implying that temporal ordering inconsistencies causes underestimation of distance effects. As expected, the structural housing characteristics do not exhibit any substantial variation across models, being mostly unaffected by spatial dependence and temporal ordering.

Looking at the quarterly dummies, OLS and ML1 exhibit very similar coefficient magnitudes, which increase significantly in ML2. The magnitudes of these coefficients are subsequently reduced in ML3, being very close to OLS and ML1 after 1999. The estimates of ML3 are considered the most reliable, since it incorporates the time decay factor that directly addressed the temporal aspect of spatial effects. These results show that the temporal ordering inconsistency or ignoring spatial dependence in HP affects the estimates of house price levels over time, which are often used to derive house price indices. Can and Megbolugbe (1997), employing data from only a single quarter, did not examine such effects.

We employ the Akaike Information Criterion (AIC) and Bayesian Information Criterion (BIC) to compare the models with respect to overall goodness of fit. In the section 5.1 we mentioned that because $\mathrm{W}_{\alpha}$ contains double the information of $\mathrm{W}_{\beta}$, we expect the equivalent model, ML1, to fit the data better, albeit by overestimating spatial dependence due to the 
temporal ordering inconsistency. This is confirmed by both AIC and BIC, ML1 fits the data best compared to all other models.

More importantly, ML3, the model that incorporates time decay into the spatial dependence pattern, provides a better fit to the data than either ML2 or OLS. This demonstrates that the time decay captures additional variation in the data, without contributing to spatial dependence overestimation, rather negating it. Compared to ML2, there is an increase in the magnitude of the aircraft noise coefficient in ML3, which is our preferred model. The NDI of 0.493 is broadly consistent with the HP aircraft noise literature that does not account for spatial dependence and lower than the 0.646 NDI of our OLS model. However, we believe it is the only robust estimate for aircraft noise from a spatial HP model.

In our data aircraft noise introduces on average $8.59 \mathrm{dBA}$ above the $55 \mathrm{dBA}$ background noise. Given the 0.493 NDI from ML3, a complete removal of aircraft noise would also remove a depreciation of $8632.7 €^{11}$ per house on average, if say the Airport was closed. It was actually closed on March 2001 and a new Athens International Airport started operations more than $20 \mathrm{kms}$ away in a more sparsely populated area.

\section{Conclusions}

This paper has identified and defined the temporal ordering inconsistency found in crosssectional HP literature for valuing environmental commodities. The temporal ordering inconsistency leads to overestimation of spatial dependence, underestimating the effects of proximity to (dis)amenities and possibly the house price development over time. The Lagrange multiplier tests, employed as guidance for model selection, were also affected by this inconsistency. Spatial weight matrices have been developed to overcome this by ordering the data from the "furthest in the past" to the latest house sale, setting to zero all the values of the upper triangle square matrix and using only the lower triangle. Our preferred specification also introduces a time decay factor to the distance weights that specify the connection in space between the observations, directly addressing the temporal aspect of spatial effects.

\footnotetext{
${ }^{11}$ This value refers to the base category (coastal area), for the non-coastal area the figures is $6705.1 €$. All money values are in 2001 price levels.
} 
We note that Bateman et al. (2004) attributed the failure to produce statistically significant aircraft noise estimates to aircraft noise being less localised than other sources. Hence, these estimates were subsumed in their treatment of spatial effects. We agree with this observation and we have shown that the temporal ordering inconsistency is responsible for subsuming aircraft noise estimates in our data, leading to undervaluation of this externality.

Our preferred model with the time decay factor produced the best fit to the data among the models free from temporal ordering inconsistency, obtaining our preferred NDI estimate of 0.493. We consider this the first robust estimate of aircraft noise valuation from a spatial HP model. This is also the first HP study for Athens and Greece implying a potential benefit from the Airport closure of $8632.7 €$ per residential property in the study area at the time.

Our treatment of aircraft noise can also be considered a step forward, since it is not a crude cut-off point that does not capture any effects below it. Our specification captures the effect of aircraft noise on the housing market above the general noise level in the area, even if aircraft noise effects are very low when dominated from other noise sources.

Clearly there are many areas for future investigation. We would like to test this approach on other data sets, developing further the specification of the time decay factor and combining it with different specifications of spatial weights. Additionally there is scope for improving the treatment of background noise. Although a common 55dBA assumption is not unreasonable as an average for this data set it will clearly include under and over-estimations.

Acknowledgments

We would like to thank EUROCONTROL Experimental Centre for funding this research and especially Ted Elliff and Ian Fuller. We also owe thanks to Yiannis Kapanidis for his help with the GIS modelling and Robert Franzese and Jude Hays for their insight to spatial dependence issues. The content of the paper and any opinions expressed are the sole responsibility of the authors. 


\section{Reference}

Allen, J., Barlow, J., Leal, J., Maloutas, T., Padovani, L., 2004. Housing and Welfare in Southern Europe. Oxford, UK: Blackwell Publishing

Andersson, H., Jonsson, L., Ögren, M., 2010. Property Prices and Exposure to Multiple Noise Sources: Hedonic Regression with Road and Railway Noise. Environmental and Resource Economics, 45, 73-89

Anselin, L., 2010. Thirty years of spatial econometrics. Papers in Regional Science, 89, 3-25 Anselin, L., 2006. Spatial econometrics. In: T. Mills, K. Patterson, eds. Palgrave handbook of econometrics, vol. 1. In: Econometric Theory. Basingstoke: Palgrave Macmillan, 901-969

Anselin, L., 2003. Spatial externalities, spatial multipliers, and spatial econometrics. International Regional Science Review, 26, 153 - 166

Anselin, L., 2002. Under the Hood: Issues in the Specification and Interpretation of Spatial Regression Models. Agricultural Economics, 27, 247 - 67

Anselin, L., 1988. Lagrange multiplier test diagnostics for spatial dependence and heterogeneity. Geographical Analysis, 20, 1-17

Anselin, L., Bera, A., Florax, R.J., Yoon, M., 1996. Simple diagnostic tests for spatial dependence. Regional Science and Urban Economics, 26, 77-104

Baranzini, A., Ramirez, J.V., 2005. Paying for quietness: the impact of noise on Geneva rents. Urban studies, 42, 633-646

Barry, R.P., Pace, R.K., 1999. Monte Carlo estimates of the log determinant of large sparse matrices. Linear Algebra and its Applications, 289, 41-54

Bateman, I., Day, B., Lake, I., Lovett, A., 2001. The effect of road traffic noise on residential property values: a literature review and hedonic pricing study. Scottish Executive Development Department, Edinburgh, UK

Bateman, I., Day, B., Lake, I., 2004. The valuation of transport-related noise in Birmingham. Non-technical report to Department for Transport, University of East Anglia, UK

Berglund, B., Lindvall, T., Schwela, D.H., 1999. Guidelines for Community Noise. World Health Organisation Geneva, Expert Task Force Meeting Guideline Document, April 1999, London, United Kingdom

Can, A., Megbolugbe, I., 1997. Spatial Dependence and House Price Index Construction. Journal of Real Estate Finance and Economics, 14, 203-222

Chalermpong, S., 2010. Impact of Airport Noise on Property Values: Case of Suvarnabhumi International Airport, Bangkok, Thailand. Journal of the Transportation Research Board, $2177,8-16$ 


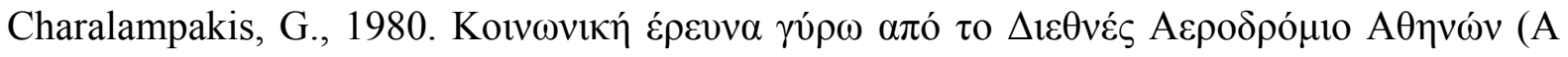

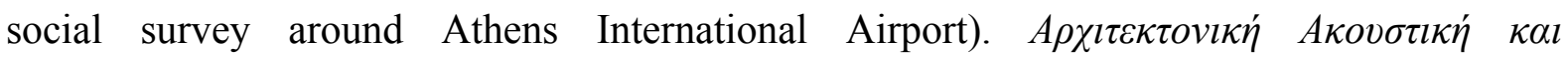

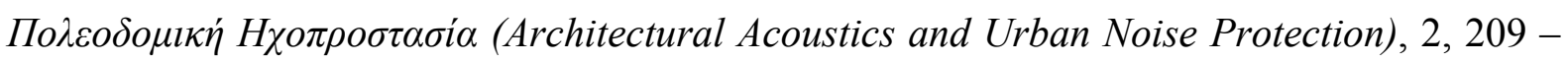
215, Volos, Greece (article in Greek)

Cohen, J.P., Coughlin, C.C., 2008. Spatial hedonic models of airport noise, proximity, and housing prices, Journal of Regional Science 48, 859-878

Conway, D., Li, C.Q., Wolch, J., Kahle, C., Jerrett, M., 2010. A Spatial Autocorrelation Approach for Examining the Effects of Urban Greenspace on Residential Property Values. Journal of Real Estate Finance and Economics, 41:150-169

Day, B., Bateman, I., Lake, I., 2007. Beyond implicit prices: recovering theoretically consistent and transferable values for noise avoidance from a hedonic property price model. Environmental and Resource Economics, 37, 211-232

Dekkers, J.E.C., Van der Straaten, J.W., 2009. Monetary valuation of aircraft noise: A hedonic analysis around Amsterdam airport. Ecological Economics, 68, 2850-2858

European Environment Agency, 2010. Towards a resource-efficient transport system, TERM 2009: indicators tracking transport and environment in the European Union. EEA Report No2/2010

European Council, 2002. Directive 2002/30/EC on the establishment of rules and procedures with regard to the introduction of noise-related operating restrictions at Community airports. Official Journal of the European Communities, L 85/40

Fellmann, J.D, Getis, A., Getis, J., 2003. Human geography: landscapes of human activities. $7^{\text {th }}$ ed. Boston: McGraw Hill

Franzese, Jr. R. J., Hays, J.C., 2008. Empirical Models of Spatial Interdependence. In: J.M. Box-Steffensmeier, H. E. Brady, D. Collier, eds. The Oxford Handbook of Political Methodology vol 7. Oxford, UK: Oxford University Press, 570-604

Gelfand, A.E., Ecker, M.D., Knight J.R., Sirmans C. F., 2004. The Dynamics of Location in Home Price. The Journal of Real Estate Finance and Economics, 29, 149-166

Hui, E.C.M., Chau, C.K., Pun, L., Law, M.Y., 2007. Measuring the neighboring and environmental effects on residential property value: Using spatial weighting matrix. Building and Environment, 42, 2333-2343

Kim, C.W., Phipps, T.T., Anselin, L., 2003. Measuring the benefits of air quality improvement: a spatial hedonic approach. Journal of Environmental Economics and Management, 45, 24-39 
Miedema, H.M.E., 2007. Annoyance Caused by Environmental Noise: Elements for Evidence-Based Noise Policies. Journal of Social Issues, 63, 41-57

Miedema, H.M.E., Vos, H., De Jong, R.G., 2000. Community reaction to aircraft noise: timeof-day penalty and trade off between levels of overflights. Journal of the Acoustical Society of America, 107, 3245-3253

National Statistical Service of Greece, 2003. Statistical Data for Greece (in Greek) [online].

General Secretariat of National Statistical Service of Greece, Ministry of Economy and Finance, Piraeus, Greece. Available from:

http://www.statistics.gr/StatMenu.asp [accessed on 22/10/2005]

Nelson, J. P., 1980. Airports and property values: a survey of recent evidence. Journal of Transport Economics and Policy, 14, 37-52

Nelson, J. P., 2004. Meta-analysis of airport noise and hedonic property values: problems and prospects. Journal of Transport Economics and Policy, 38, 1 - 28

Nelson, J. P., 2008. Hedonic Property Value Studies of Transportation Noise: Aircraft and Road Traffic. In: A. Baranzini, J. Ramirez, C. Schaerer, P. Thalman, eds. Hedonic Methods in Housing Markets, vol. 3. In: Pricing Environmental Amenities and Segregation. New York, USA: Springer, 55-82

OECD, 2006. Consumer Price Index for Housing [online]. Available from OECD StatExtracts: http://stats.oecd.org/wbos [accessed on 23/09/2008]

Pace, R. K., Barry, R., Clapp, J.M., Rodriguez, M., 1998. Spatiotemporal Autoregressive Models of Neighborhood Effects. Journal of Real Estate Finance and Economics, 17, 15-33

Palmquist, R. B., 1992. Valuing Localized Externalities. Journal of Urban Economics, 31, $59-68$

Pryce, G., Gibb, K., 2006. Submarket Dynamics of Time to Sale. Real Estate Economics. 34, $377-415$

Rich, J.H., Nielsen, O.A., 2004. Assessment of traffic noise impacts, International Journal of environmental studies. 61, 19-29

Salvi, M., 2008. Spatial Estimation of the Impact of Airport Noise on Residential Housing Prices. Swiss Journal of Economics and Statistics, 2008-IV-3, 577-606.

Schipper, Y., Nijkamp, P., Rietveld P., 1998. Why do aircraft noise value estimates differ? A meta-analysis. Journal of Air Transport Management, 4, 117 - 124

Taylor, S.M., Hall, F.L., Birnie, S.E., 1987. Transportation noise annoyance: testing of a probabilistic model. Journal of Sound and Vibration, 117, 95-113 
Thanos, S., Wardman, M.R., Bristow, A.L., 2011. Valuing aircraft noise: Stated Choice experiments reflecting inter-temporal noise changes from airport relocation. Environmental and Resource Economics, 50, 559-583.

Theebe, M.A., 2004. Planes, trains, and automobiles: the impact of traffic noise on house prices. Journal of Real Estate Finance and Economics, 28, 209-234

Tobler, W., 1970. A computer movie simulating urban growth in the Detroit region, Economic Geography, 46, 234-240

Tomkins, J., Topham, N., Twomey, J., Ward, R., 1998. Noise versus access: The impact of an airport in the urban property market. Urban Studies, 35, 243 - 258

Wadud, Z., 2010. Meta-Regression of NDIs around Airports: Effect of Income/Wealth, paper presented at the $12^{\text {th }}$ World Conference on Transport Research, $11^{\text {th }}$ to $15^{\text {th }}$ July 2010 , Lisbon, Portugal

Watkins, C. A., 2001. The definition and identification of housing submarkets. Environment and Planning A. 33, $2235-2253$

White M., Watkins, C. A., 2004. Spatial, house-type and temporal variations in time on the market. Presented at the $11^{\text {th }}$ European Real Estate Society Conference, $2^{\text {nd }}$ to $5^{\text {th }}$ June 2004, Milan, Italy

Zuehlke, T.W., 1987. Duration dependence in the housing market. The Review of Economics and Statistics, 69, 701 - 709 
Appendix 1: The HP Models

\begin{tabular}{|c|c|c|c|c|}
\hline Model & OLS & $\begin{array}{l}\text { ML1: } \\
\text { Full Weight (W } \alpha)\end{array}$ & $\begin{array}{l}\text { ML2: } \\
\text { Trill Weight (W } \beta)\end{array}$ & $\begin{array}{l}\text { ML3: } \\
\text { Time Decay }(\mathrm{W} \gamma)\end{array}$ \\
\hline Variable Name & Coef. & Coef. & Coef. & Coef. \\
\hline Lden_tot & $\begin{array}{l}-0.00646 * * * \\
(0.00135)\end{array}$ & $\begin{array}{l}-0.00196 \\
(0.00137)\end{array}$ & $\begin{array}{l}-0.00454 * * * \\
(0.00136)\end{array}$ & $\begin{array}{l}-0.00493 * * * \\
(0.00135)\end{array}$ \\
\hline sq meters & $\begin{array}{l}0.00421 * * * \\
(0.00016)\end{array}$ & $\begin{array}{l}0.00427 * * * \\
(0.00015)\end{array}$ & $\begin{array}{l}0.00425 * * * \\
(0.00015)\end{array}$ & $\begin{array}{l}0.00422 * * * \\
(0.00015)\end{array}$ \\
\hline room1_2 & $\begin{array}{l}-0.68726^{* * *} \\
(0.02303)\end{array}$ & $\begin{array}{l}-0.68876^{* * * *} \\
(0.02202)\end{array}$ & $\begin{array}{l}-0.68642 * * * \\
(0.02246)\end{array}$ & $\begin{array}{l}-0.68121 * * * \\
(0.02247)\end{array}$ \\
\hline room3 & $\begin{array}{l}-0.29225^{* * *} \\
(0.01791)\end{array}$ & $\begin{array}{l}-0.29934 * * * \\
(0.01714)\end{array}$ & $\begin{array}{l}-0.29291 * * * \\
(0.01746)\end{array}$ & $\begin{array}{l}-0.28759 * * * \\
(0.01747)\end{array}$ \\
\hline room4 & Base & Base & Base & Base \\
\hline room5 & $\begin{array}{l}0.18547 * * * \\
(0.02048)\end{array}$ & $\begin{array}{l}0.19445 * * * \\
(0.01961)\end{array}$ & $\begin{array}{l}0.18818 * * * \\
(0.01998)\end{array}$ & $\begin{array}{l}0.19133 * * * \\
(0.01999)\end{array}$ \\
\hline room6 & $\begin{array}{l}0.25689 * * * \\
(0.02409)\end{array}$ & $\begin{array}{l}0.26040 * * * \\
(0.02304)\end{array}$ & $\begin{array}{l}0.25773 * * * \\
(0.02349)\end{array}$ & $\begin{array}{l}0.25723 * * * \\
(0.02348)\end{array}$ \\
\hline room7 & $\begin{array}{l}0.28137 * * * \\
(0.02756)\end{array}$ & $\begin{array}{l}0.28589 * * * \\
(0.02636)\end{array}$ & $\begin{array}{l}0.28617 * * * \\
(0.02688)\end{array}$ & $\begin{array}{l}0.28986^{* * *} \\
(0.02690)\end{array}$ \\
\hline House $>10 y r$ & $\begin{array}{l}-0.01933 \\
(0.01970)\end{array}$ & $\begin{array}{l}-0.02075 \\
(0.01884)\end{array}$ & $\begin{array}{l}-0.01945 \\
(0.01921)\end{array}$ & $\begin{array}{l}-0.01897 \\
(0.01920)\end{array}$ \\
\hline House 6-9yr & $\begin{array}{l}-0.01657 \\
(0.01784)\end{array}$ & $\begin{array}{l}-0.01235 \\
(0.01707)\end{array}$ & $\begin{array}{l}-0.01439 \\
(0.01740)\end{array}$ & $\begin{array}{l}-0.01551 \\
(0.01739)\end{array}$ \\
\hline H_Age_B & Base & Base & Base & Base \\
\hline floors_7-8 & $\begin{array}{l}0.05676 \\
(0.05249)\end{array}$ & $\begin{array}{l}0.10853 * * \\
(0.05047)\end{array}$ & $\begin{array}{l}0.07231 \\
(0.05126)\end{array}$ & $\begin{array}{l}0.06387 \\
(0.05117)\end{array}$ \\
\hline floors_4-6 & $\begin{array}{l}0.09369 * * * \\
(0.01450)\end{array}$ & $\begin{array}{l}0.11069 * * * \\
(0.01398)\end{array}$ & $\begin{array}{l}0.10019 * * * \\
(0.01419)\end{array}$ & $\begin{array}{l}0.09867 * * * \\
(0.01416)\end{array}$ \\
\hline floors $<4$ & Base & Base & Base & Base \\
\hline detached & $\begin{array}{l}0.12209 * * * \\
(0.02392)\end{array}$ & $\begin{array}{l}0.12566 * * * \\
(0.02287)\end{array}$ & $\begin{array}{l}0.12014 * * * \\
(0.02332)\end{array}$ & $\begin{array}{l}0.12238 * * * \\
(0.02331)\end{array}$ \\
\hline semidetached & $\begin{array}{l}0.05518 * * \\
(0.02432)\end{array}$ & $\begin{array}{l}0.04408^{*} \\
(0.02328)\end{array}$ & $\begin{array}{l}0.05755 * * \\
(0.02372)\end{array}$ & $\begin{array}{l}0.05690 * * \\
(0.02370)\end{array}$ \\
\hline flat & Base & Base & Base & Base \\
\hline garage & $\begin{array}{l}0.08984 * * * \\
(0.01231)\end{array}$ & $\begin{array}{l}0.09136 * * * \\
(0.01178)\end{array}$ & $\begin{array}{l}0.08726 * * * \\
(0.01201)\end{array}$ & $\begin{array}{l}0.08608 * * * \\
(0.01202)\end{array}$ \\
\hline non_coastal & $\begin{array}{l}-0.24926^{* * *} \\
(0.02852)\end{array}$ & $\begin{array}{l}-0.35083^{* * *} \\
(0.02915)\end{array}$ & $\begin{array}{l}-0.30166^{* * *} \\
(0.02931)\end{array}$ & $\begin{array}{l}-0.26541 * * * \\
(0.02793)\end{array}$ \\
\hline Coastal_area & Base & Base & Base & Base \\
\hline d_sports & $\begin{array}{l}-9.1 \mathrm{E}-05 * * * \\
(1.9 \mathrm{E}-05)\end{array}$ & $\begin{array}{l}-6.0 \mathrm{E}-05^{* * *} \\
(1.8 \mathrm{E}-05)\end{array}$ & $\begin{array}{l}-8.4 \mathrm{E}-05^{* * *} \\
(1.9 \mathrm{E}-05)\end{array}$ & $\begin{array}{l}-8.2 \mathrm{E}-05 * * * \\
(1.9 \mathrm{E}-05)\end{array}$ \\
\hline d_public_serv & $\begin{array}{l}1.2 \mathrm{E}-05 \\
(2.2 \mathrm{E}-05)\end{array}$ & $\begin{array}{l}-5.3 \mathrm{E}-06 \\
(2.1 \mathrm{E}-05)\end{array}$ & $\begin{array}{l}8.9 \mathrm{E}-06 \\
(2.1 \mathrm{E}-05)\end{array}$ & $\begin{array}{l}6.9 \mathrm{E}-06 \\
(2.1 \mathrm{E}-05)\end{array}$ \\
\hline d_plaza & $-1.3 \mathrm{E}-04 * * *$ & $-9.4 \mathrm{E}-05 * * *$ & $-1.2 \mathrm{E}-04 * * *$ & $-1.2 \mathrm{E}-04 * * *$ \\
\hline
\end{tabular}




\begin{tabular}{|c|c|c|c|c|}
\hline Model & OLS & $\begin{array}{l}\text { ML1: } \\
\text { Full Weight }(\mathrm{W} \alpha)\end{array}$ & $\begin{array}{l}\text { ML2: } \\
\text { Trill Weight (W } \beta)\end{array}$ & $\begin{array}{l}\text { ML3: } \\
\text { Time Decay }(\mathrm{W} \gamma)\end{array}$ \\
\hline \multirow[t]{2}{*}{ Variable Name } & Coef. & Coef. & Coef. & Coef. \\
\hline & $(3.0 \mathrm{E}-05)$ & $(2.9 \mathrm{E}-05)$ & $(2.9 \mathrm{E}-05)$ & $(2.9 \mathrm{E}-05)$ \\
\hline \multirow[t]{2}{*}{ d_school } & $1.7 \mathrm{E}-04 * * *$ & $1.1 \mathrm{E}-04 * * *$ & $1.6 \mathrm{E}-04 * * *$ & $1.5 \mathrm{E}-04 * * *$ \\
\hline & $(2.4 \mathrm{E}-05)$ & $(2.3 \mathrm{E}-05)$ & $(2.3 \mathrm{E}-05)$ & $(2.3 \mathrm{E}-05)$ \\
\hline \multirow[t]{2}{*}{ d_supermarket } & $-4.1 \mathrm{E}-05^{* * *}$ & $-2.8 \mathrm{E}-05^{* *}$ & $-3.8 \mathrm{E}-05^{* * *}$ & $-3.6 \mathrm{E}-05 * * *$ \\
\hline & $(1.4 \mathrm{E}-05)$ & $(1.3 \mathrm{E}-05)$ & $(1.4 \mathrm{E}-05)$ & $(1.4 \mathrm{E}-05)$ \\
\hline \multirow[t]{2}{*}{ d_church } & $8.1 \mathrm{E}-05^{* * *}$ & $4.8 \mathrm{E}-05^{*}$ & $6.6 \mathrm{E}-05 * *$ & $6.4 \mathrm{E}-05 * *$ \\
\hline & $(2.7 \mathrm{E}-05)$ & $(2.6 \mathrm{E}-05)$ & $(2.6 \mathrm{E}-05)$ & $(2.6 \mathrm{E}-05)$ \\
\hline \multirow[t]{2}{*}{ d_health } & $-1.9 \mathrm{E}-05$ & $-1.8 \mathrm{E}-05$ & $-2.4 \mathrm{E}-05^{*}$ & $-2.2 \mathrm{E}-05$ \\
\hline & $(1.4 \mathrm{E}-05)$ & $(1.4 \mathrm{E}-05)$ & $(1.4 \mathrm{E}-05)$ & $(1.4 \mathrm{E}-05)$ \\
\hline \multirow[t]{2}{*}{ d_main_rd } & $9.3 \mathrm{E}-05 * * *$ & $4.5 \mathrm{E}-05$ & $6.6 \mathrm{E}-05^{* *}$ & $7.1 \mathrm{E}-05 * *$ \\
\hline & $(3.1 \mathrm{E}-05)$ & $(3.0 \mathrm{E}-05)$ & $(3.1 \mathrm{E}-05)$ & $(3.1 \mathrm{E}-05)$ \\
\hline \multirow[t]{2}{*}{ d_air_4km } & $3.2 \mathrm{E}-05 * * *$ & $2.8 \mathrm{E}-05 * * *$ & $3.6 \mathrm{E}-05 * * *$ & $3.1 \mathrm{E}-05 * * *$ \\
\hline & $(6.7 \mathrm{E}-06)$ & $(6.5 \mathrm{E}-06)$ & $(6.6 \mathrm{E}-06)$ & $(6.6 \mathrm{E}-06)$ \\
\hline \multirow[t]{2}{*}{ Akto_300m } & $0.04203 * *$ & 0.02831 & $0.03873 * *$ & $0.03561 * *$ \\
\hline & $(0.01854)$ & (0.01779) & $(0.01809)$ & $(0.01810)$ \\
\hline \multirow[t]{2}{*}{ y95q1 } & $-0.37105 * * *$ & $-0.38219 * * *$ & $-0.67981 * * *$ & $-0.53115 * * *$ \\
\hline & $(0.03636)$ & $(0.03479)$ & $(0.06503)$ & $(0.04491)$ \\
\hline \multirow[t]{2}{*}{ y95q2 } & $-0.47472 * * *$ & $-0.48113 * * *$ & $-0.77176^{* * *}$ & $-0.59768 * * *$ \\
\hline & $(0.03594)$ & $(0.03437)$ & $(0.06308)$ & $(0.04094)$ \\
\hline \multirow[t]{2}{*}{ y95q3 } & $-0.50644 * * *$ & $-0.51521 * * *$ & $-0.79166^{* * *}$ & $-0.61010 * * *$ \\
\hline & $(0.03517)$ & $(0.03364)$ & $(0.06093)$ & $(0.03865)$ \\
\hline \multirow[t]{2}{*}{ y95q4 } & $-0.45703 * * *$ & $-0.46232 * * *$ & $-0.72939 * * *$ & $-0.54233 * * *$ \\
\hline & $(0.03883)$ & $(0.03714)$ & $(0.06121)$ & $(0.04060)$ \\
\hline \multirow[t]{2}{*}{ y96q1 } & $-0.42217 * * *$ & $-0.43064 * * *$ & $-0.68209 * * *$ & $-0.50894 * * *$ \\
\hline & $(0.03477)$ & $(0.03326)$ & $(0.05706)$ & $(0.03704)$ \\
\hline \multirow[t]{2}{*}{ y96q2 } & $-0.44960 * * *$ & $-0.45616^{* * *}$ & $-0.69755 * * *$ & $-0.52558 * * *$ \\
\hline & $(0.03602)$ & $(0.03445)$ & $(0.05613)$ & $(0.03747)$ \\
\hline \multirow[t]{2}{*}{ y96q3 } & $-0.50018 * * *$ & $-0.49430 * * *$ & $-0.73431 * * *$ & $-0.56531 * * *$ \\
\hline & $(0.03476)$ & $(0.03325)$ & $(0.05346)$ & $(0.03569)$ \\
\hline \multirow{2}{*}{ y96q4 } & $-0.38484 * * *$ & $-0.38464 * * *$ & $-0.60548 * * *$ & $-0.44081 * * *$ \\
\hline & $(0.03861)$ & $(0.03693)$ & $(0.05418)$ & $(0.03885)$ \\
\hline \multirow[t]{2}{*}{ y97q1 } & $-0.28022 * * *$ & $-0.28249 * * *$ & $-0.49446 * * *$ & $-0.34503 * * *$ \\
\hline & $(0.03674)$ & $(0.03513)$ & $(0.05210)$ & $(0.03751)$ \\
\hline \multirow[t]{2}{*}{ y97q2 } & $-0.33387 * * *$ & $-0.33851 * * *$ & $-0.53784 * * *$ & $-0.39293 * * *$ \\
\hline & $(0.03533)$ & $(0.03379)$ & $(0.04984)$ & $(0.03591)$ \\
\hline \multirow[t]{2}{*}{ y97q3 } & $-0.29993 * * *$ & $-0.30098 * * *$ & $-0.48805 * * *$ & $-0.34601 * * *$ \\
\hline & $(0.03354)$ & $(0.03207)$ & $(0.04661)$ & $(0.03364)$ \\
\hline \multirow[t]{2}{*}{$\mathrm{y} 97 \mathrm{q} 4$} & $-0.38116^{* * *}$ & $-0.37546 * * *$ & $-0.55582 * * *$ & $-0.42096 * * *$ \\
\hline & $(0.04270)$ & $(0.04084)$ & $(0.05181)$ & $(0.04218)$ \\
\hline \multirow[t]{2}{*}{ y98q1 } & $-0.24365 * * *$ & $-0.21938 * * *$ & $-0.40130 * * *$ & $-0.30476 * * *$ \\
\hline & $(0.03734)$ & $(0.03579)$ & $(0.04583)$ & $(0.03789)$ \\
\hline \multirow[t]{2}{*}{ y98q2 } & $-0.23354 * * *$ & $-0.24206 * * *$ & $-0.39512 * * *$ & $-0.29039 * * *$ \\
\hline & $(0.03131)$ & $(0.02995)$ & $(0.04179)$ & $(0.03205)$ \\
\hline
\end{tabular}




\begin{tabular}{|c|c|c|c|c|}
\hline Model & OLS & $\begin{array}{l}\text { ML1: } \\
\text { Full Weight }(\mathrm{W} \alpha)\end{array}$ & $\begin{array}{l}\text { ML2: } \\
\text { Trill Weight (W } \beta)\end{array}$ & $\begin{array}{l}\text { ML3: } \\
\text { Time Decay }(W \gamma)\end{array}$ \\
\hline Variable Name & Coef. & Coef. & Coef. & Coef. \\
\hline y98q3 & $\begin{array}{l}-0.18221^{* *} \\
(0.07129)\end{array}$ & $\begin{array}{l}-0.17426^{* *} \\
(0.06818)\end{array}$ & $\begin{array}{l}-0.32412 * * * \\
(0.07389)\end{array}$ & $\begin{array}{l}-0.22529 * * * \\
(0.06987)\end{array}$ \\
\hline y98q4 & $\begin{array}{l}-0.20849 * * * \\
(0.03164)\end{array}$ & $\begin{array}{l}-0.21070 * * * \\
(0.03025)\end{array}$ & $\begin{array}{l}-0.34575 * * * \\
(0.03923)\end{array}$ & $\begin{array}{l}-0.25492 * * * \\
(0.03185)\end{array}$ \\
\hline y99q1 & $\begin{array}{l}-0.10104 * * * \\
(0.02739)\end{array}$ & $\begin{array}{l}-0.11242 * * * \\
(0.02621)\end{array}$ & $\begin{array}{l}-0.22458 * * * \\
(0.03448)\end{array}$ & $\begin{array}{l}-0.11354 * * * \\
(0.02678)\end{array}$ \\
\hline y99q2 & $\begin{array}{l}-0.16852 * * * \\
(0.02923)\end{array}$ & $\begin{array}{l}-0.16902 * * * \\
(0.02796)\end{array}$ & $\begin{array}{l}-0.26490 * * * \\
(0.03320)\end{array}$ & $\begin{array}{l}-0.15325 * * * \\
(0.02861)\end{array}$ \\
\hline y99q3 & $\begin{array}{l}-0.17800 * * * \\
(0.04334)\end{array}$ & $\begin{array}{l}-0.19939 * * * \\
(0.04150)\end{array}$ & $\begin{array}{l}-0.26714 * * * \\
(0.04509)\end{array}$ & $\begin{array}{l}-0.17786^{* * *} \\
(0.04223)\end{array}$ \\
\hline y99q4 & $\begin{array}{l}-0.21614 * * * \\
(0.07124)\end{array}$ & $\begin{array}{l}-0.23333 * * * \\
(0.06815)\end{array}$ & $\begin{array}{l}-0.29831 * * * \\
(0.07096)\end{array}$ & $\begin{array}{l}-0.24284^{* * *} \\
(0.06958)\end{array}$ \\
\hline $\mathrm{y} 00 \mathrm{q} 1$ & $\begin{array}{l}-0.03739 \\
(0.02727)\end{array}$ & $\begin{array}{l}-0.05575 * * \\
(0.02615)\end{array}$ & $\begin{array}{l}-0.11391 * * * \\
(0.02983)\end{array}$ & $\begin{array}{l}-0.07356^{* * *} \\
(0.02730)\end{array}$ \\
\hline $\mathrm{y} 00 \mathrm{q} 2$ & $\begin{array}{l}-0.04355 \\
(0.02817)\end{array}$ & $\begin{array}{l}-0.05826 * * \\
(0.02698)\end{array}$ & $\begin{array}{l}-0.09467 * * * \\
(0.02891)\end{array}$ & $\begin{array}{l}-0.03048 \\
(0.02755)\end{array}$ \\
\hline $\mathrm{y} 00 \mathrm{q} 3$ & $\begin{array}{l}-0.08003 * * \\
(0.03595)\end{array}$ & $\begin{array}{l}-0.08448 * * \\
(0.03438)\end{array}$ & $\begin{array}{l}-0.11089 * * * \\
(0.03547)\end{array}$ & $\begin{array}{l}-0.06170^{*} \\
(0.03518)\end{array}$ \\
\hline $\begin{array}{l}\text { y00q4 } \\
\text { constant }\end{array}$ & $\begin{array}{l}\text { Base } \\
12.134 * * * \\
0.09447)\end{array}$ & $\begin{array}{l}\text { Base } \\
12.229 * * * \\
0.09085)\end{array}$ & $\begin{array}{l}\text { Base } \\
12.315^{* * *} \\
0.09752)\end{array}$ & $\begin{array}{l}\text { Base } \\
12.225^{* * *} \\
(0.09339)\end{array}$ \\
\hline lambda & & $\begin{array}{l}0.0107 * * * \\
(0.00109)\end{array}$ & $\begin{array}{l}0.0095 * * * \\
(0.00169)\end{array}$ & $\begin{array}{l}0.0292 * * * \\
(0.00504)\end{array}$ \\
\hline sigma & & $0.2052 * * *$ & $0.2093 * * *$ & $0.2092 * * *$ \\
\hline Wald $\chi^{2}(48)$ & & $11738 * * *$ & $11158 * * *$ & $11040 * * *$ \\
\hline $\begin{array}{l}\text { Final LL } \\
\text { Adj R-squared }\end{array}$ & 0.868 & 265.22 & 233.93 & 234.70 \\
\hline AIC & -338.11 & -428.44 & -365.86 & -367.40 \\
\hline $\mathrm{BIC}$ & -74.12 & -153.76 & -91.18 & -92.73 \\
\hline
\end{tabular}

